\title{
NATO and the EU Confronting a Turbulent Security Environment
}

\section{Alain Faupin *}

In the face of the continuing challenges to international security, the focus for the 16th meeting of the EASSG was deliberately placed on crisis management.

It is rather obvious that discrepancies exist in Europe and within the Euro-Atlantic community over the ways and means to manage the current crises that affect stability and peace in most of the regions of the world. Terrorism is as widespread and prolific as it has ever been, but the difference is that today it relies on state-of-the-art technologies of communication, intelligence, and weaponry. Globalization is not limited to economic, social, and cultural questions; the tools of terror are globalized just as effectively as the products of progress. Terrorism has proliferated on this fertile ground and has become quicker in its actions, more effective, and more global and lethal in its results. The events of September 11 were a striking example of the new dimension of terrorism.

But terrorism is not the only form or source of crisis. More classical threats, dangers, and risks can erupt into unpredictable situations, which even the best-prepared plans may fail to foresee. Organized crime, looting of national resources by national or international interests, nationalism, ethnic exceptionalism, religious extremism, and failed economies and states often result in open crises that first affect the civilian population and then disrupt, for years or even decades, fragile or obsolescent internal and international balances.

The rich and developed North, along with its Asian and Oceanian partners, is often called upon to solve or straighten out such problematic situations. Doubtless, these states would prefer to act preventively before being compelled to intervene with their forces in a very uncertain, expensive, and time-consuming manner. Current or recent examples are provided by Iraq, Afghanistan, Bosnia, Kosovo, Macedonia, the Democratic Republic of Congo (DRC), Liberia and Sierra Leone, Cambodia and East Timor, the Philippines and Colombia, Georgia and Moldova, and the Middle East, to name only a few.

Nation-states do not share the same political and economic interests and do not react in the same ways to a given situation. International institutions and organizations are intended to take over and act in cases where states can no longer find common ground. An important issue, therefore, is the legal basis of any given intervention.

To be brief, all these questions brought our group to the conclusion that we needed to map the different avenues of crisis management at the disposal of the EU and of NATO.

* Major-General (ret.) Alain Faupin is Senior Fellow, Geneva Center for the Democratic Control of Armed Forces (DCAF), Geneva, Switzerland. 
We needed a venue and an organization. To this end, the Krakow Institute for Strategic Studies (ISS) offered to host our meeting under the benevolent and efficient authority and sponsorship of Dr. Bogdan Klich, Deputy Chairman of the Foreign Affairs Committee in the Polish Parliament and president of the Institute. This also allowed the study group to be acquainted with recent developments regarding Polish foreign policy and Poland's accession to the EU as well as the country's military involvement in Iraq, including the initial lessons learned from this deployment.

The meeting was divided into three parts: one devoted to prevention, the second concentrating on intervention, and the third on post-conflict rehabilitation. Most of the presentations fell under one of these categories, with the exception of the introductory Polish panel composed of Dr. Klich, Dr. Andrzej Karkoszka (DCAF), and Mr. Mariusz Kawczynski (MFA).

The proceedings of the meeting reflect a large diversity of views, though all have one common concern: that both EU and NATO find the right tools and mechanisms to tackle, either jointly or separately, the security crises of both the present and the future, while maintaining a permanently open channel of communication. It also became abundantly clear that the central role of NATO in a given intervention came as a result of its access to military units, its integrated command structure, and its strategic assets (intelligence, logistics, and projection of forces). The EU, though in possession of intervention capabilities (as the operation in DRC has shown), was considered perhaps better suited, for the time being, for taking care of the post-conflict rehabilitation tasks, thanks to its perhaps greater familiarity with the social, cultural, and economic aspects of many situations. As far as crisis prevention is concerned, both NATO and the EU share common responsibilities. However, probably the most difficult problem concerns coordination between the Europeans, who are generally divided on the threat assessment as well as on the avenues for action, and the Atlantic Alliance, which has to be more respectful of the world's only superpower's views and options.

Drawing conclusions from these considerations, it appeared clearly that the EuroAtlantic Security Study Group (EASSG) needed to continue its research and discussions on the three points above. It was agreed that the best way to proceed would be to divide the EASSG work force into three sub groups, each with an autonomous mandate. This remains to be organized in detail: the next meeting in Bratislava (11-13 January 2004) will address this question.

Finally, I would like to once more thank Dr. Bogdan Klich for his critical support; the members of his staff, Dr. Andrzej Sokolowski and Mr. Stefan Kurek, who made this meeting a success; as well as Mr. Rafal Domisiewicz, who was instrumental in defining the topic and in editing the proceedings. 